Supporting information

\title{
Stabilizing Metallic Iron Nanoparticles by Conformal Graphitic Carbon Coating for High-Rate Anode in Ni-Fe Batteries
}

Xu Wu, ${ }^{a, b}$ Huanhuan Zhang, ${ }^{a}$ Ke-Jing Huang, ${ }^{c}$ Zheng $C h e n^{b, d, e *}$

${ }^{a}$ College of Physics and Electronic Engineering, Xinyang Normal University, Xinyang 464000, P. R.

\section{China}

${ }^{b}$ Department of NanoEngineering, University of California San Diego, La Jolla, CA 92093

${ }^{c}$ College of Chemistry and Chemical Engineering, Xinyang Normal University, Xinyang 464000,

China

${ }^{d}$ Program of Chemical Engineering, University of California San Diego, La Jolla, CA 92093

eSustainable Power \& Energy Center (SPEC), University of California San Diego, La Jolla, CA 92093

*Correspondence to: zhengchen@eng.ucsd.edu
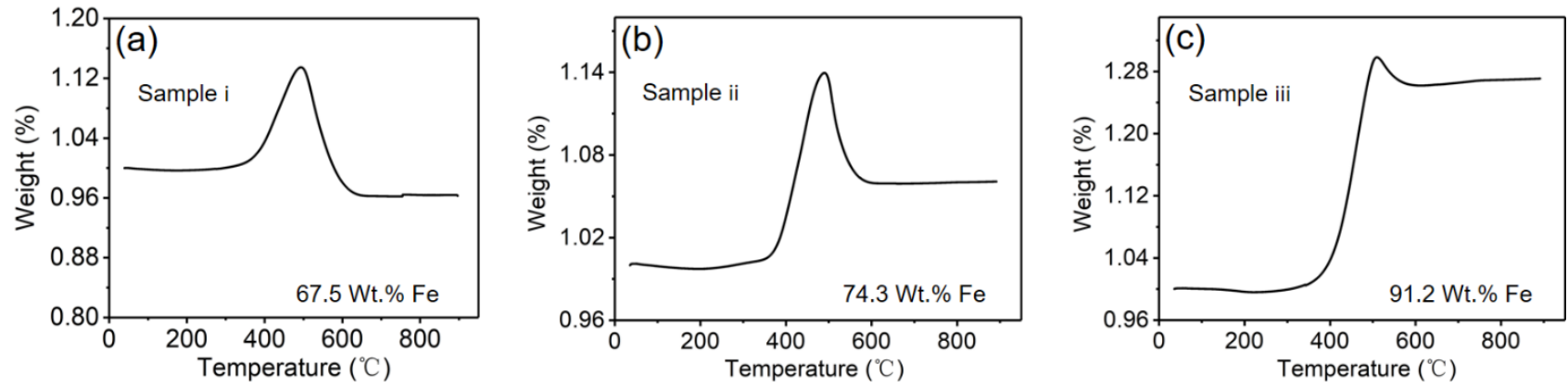

Figure S1. Thermogravimetric analysis (TGA) profiles of C- Fe nanoparticles prepared from $\mathrm{Na}_{2} \mathrm{CO}_{3}$ coated Fe nanoparticles and sucrose with mass ratios of (a) 5:6 (sample i), (b) 5:4 (sample ii) and (c) 5:2 (sample iii) under nitrogen flow at $900{ }^{\circ} \mathrm{C}$. The weight increase of the samples at first was due to the oxidation of $\mathrm{Fe}$ to $\mathrm{Fe}_{2} \mathrm{O}_{3}$; then the following weight loss was resulted from carbon combustion, which left only $\mathrm{Fe}_{2} \mathrm{O}_{3}$ after the test. The mass ratio of $\mathrm{Fe}$ (wt.\%) in the composites was calculated to be $67.5 \%, 74.3 \%$ and $91.2 \%$ for sample i, ii and iii, respectively. 


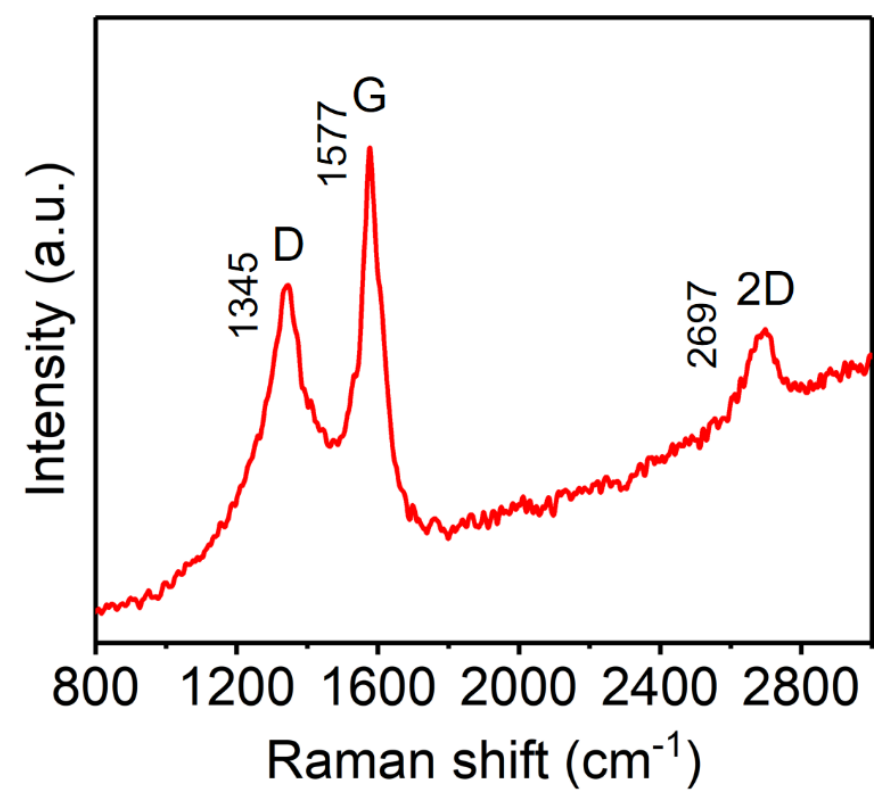

Figure S2. Raman spectrum of sample ii C-Fe (with 74 wt.\% of Fe). 


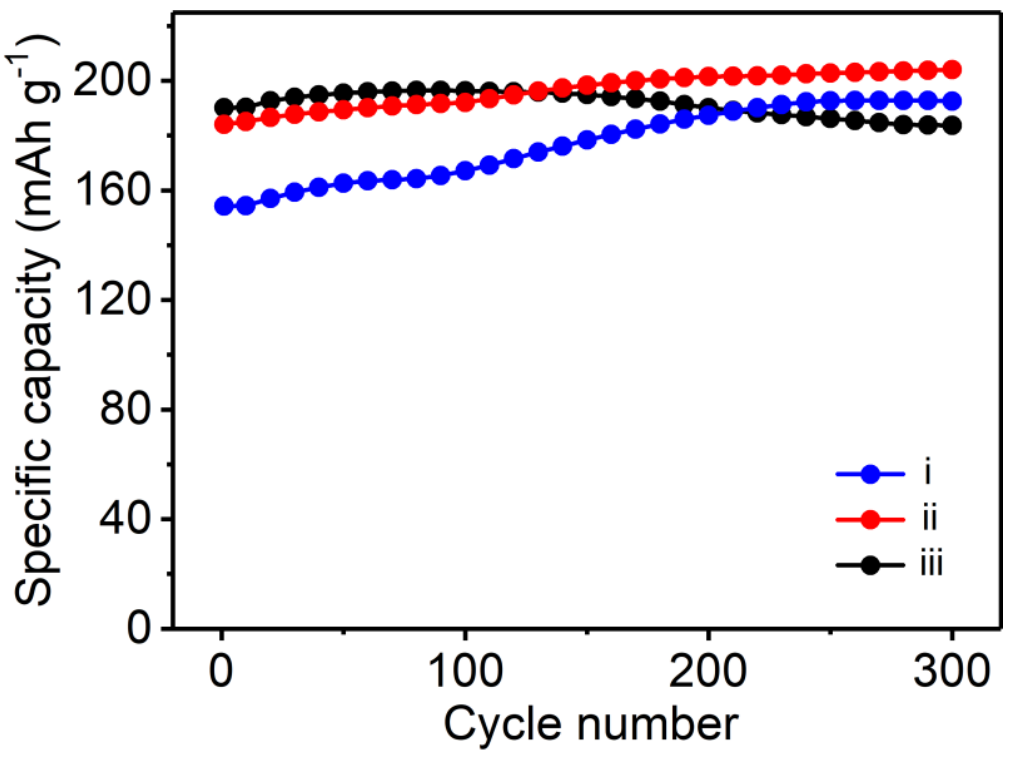

Figure S3. Cycling performance of sample i, ii and iii based on cyclic voltammetry test results at scan rate of $10 \mathrm{mV} \mathrm{s}^{-1}$ after activation. 


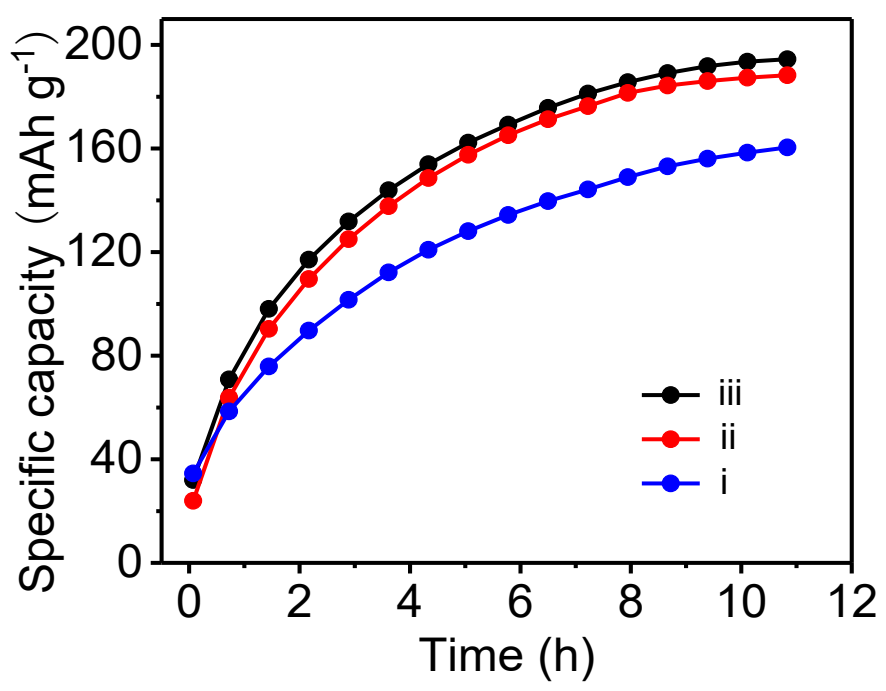

Figure S4. Specific capacities based on the mass of composites of sample i, ii and iii during the activation process. The activation was carried out through the $\mathrm{CV}$ process at relatively fast scan rate of $10 \mathrm{mVs}^{-1}$ for 150 cycles, which corresponds to a total activation time of $10.8 \mathrm{hrs}$. 


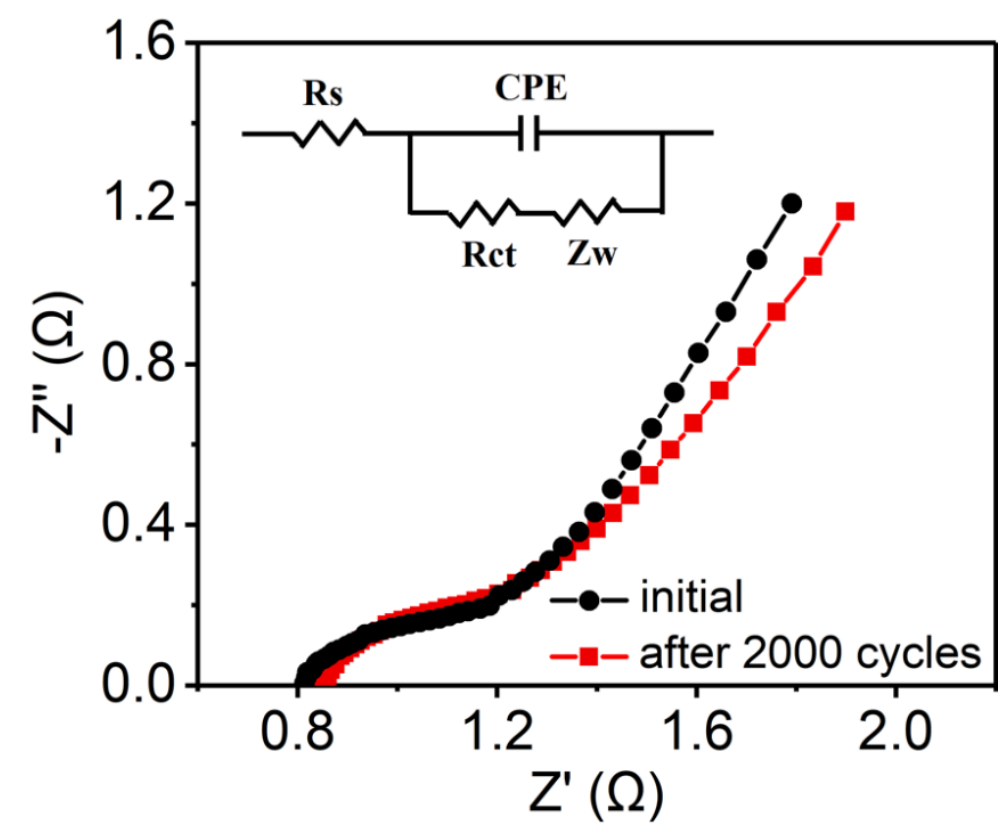

Figure S5. Nyquist plots of C- Fe anode (74 wt.\% of Fe) before and after 2000 cycles at the open circuit potentials of -0.767 and $-0.770 \mathrm{~V}$, respectively. The intersections of the curves at the real axis show the Ohmic resistances $\left(R_{S}\right)$; the diameter of the semicircle at the high frequency region is related to the charge-transfer resistance $\left(R_{c t}\right)$, and the slope of the low-frequency tail is associated with the ion diffusion rate. The equivalent circuit used to fit the EIS curves is shown in the inset. $Z_{w}$ and CPE are the Warburg impedance and the constant phase element, respectively. 

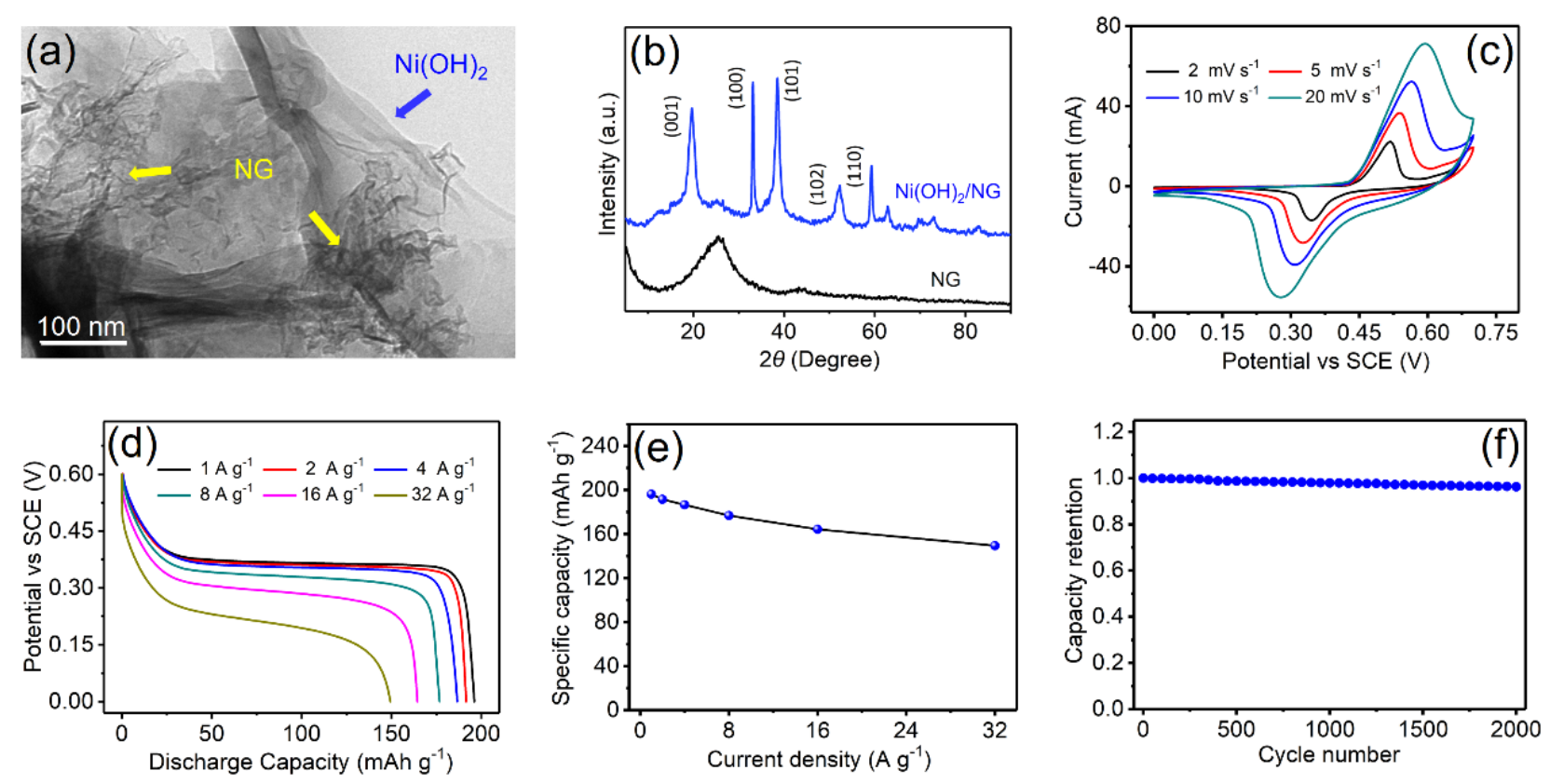

Figure S6. Characterization and electrochemical performance of the prepared $\mathrm{Ni}(\mathrm{OH})_{2} / \mathrm{NG}$ cathode. (a) TEM image of the prepared $\mathrm{Ni}(\mathrm{OH})_{2} / \mathrm{NG}$. The $\mathrm{Ni}(\mathrm{OH})_{2}$ and $\mathrm{NG}$ were marked with blue and yellow arrows, respectively. (b) XRD patterns of $\mathrm{NG}$ and $\mathrm{Ni}(\mathrm{OH})_{2} / \mathrm{NG}$. (c) $\mathrm{CV}$ curves at different scan rates $\left(2-20 \mathrm{mV} \mathrm{s}^{-1}\right)$, (d) Discharging curves at different current densities (charging was carried out with a fixed current density of $4 \mathrm{~A} \mathrm{~g} \mathrm{~g}^{-1}$ to $0.6 \mathrm{~V} v s$. SCE), (e) Specific capacities at different current densities, and (f) Cycling stability of the prepared $\mathrm{Ni}(\mathrm{OH})_{2} / \mathrm{NG}$ cathode. All the current densities and specific capacities were normalized based on the mass of the composite electrode materials. Mass loading of the tested electrode was $1.5 \mathrm{mg} \mathrm{cm}^{-2}$. 


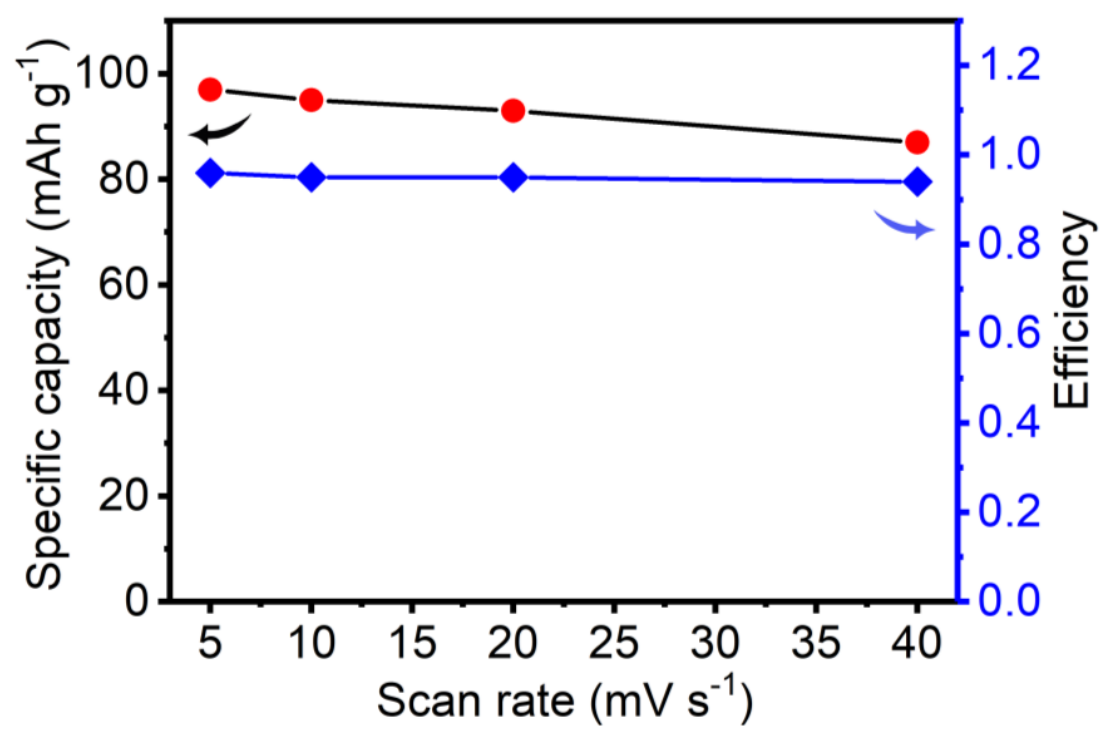

Figure S7. Specific capacity of the assembled Ni-Fe full at various scan rates. Specific capacities of 97, 94, 92, $87 \mathrm{mAh} \mathrm{g}^{-1}$ with all Coulombic efficiency higher than 0.94 were obtained based on the mass of composite at scan rates of 5, 10, 20 and $40 \mathrm{mV} \mathrm{s}^{-1}$, respectively. 


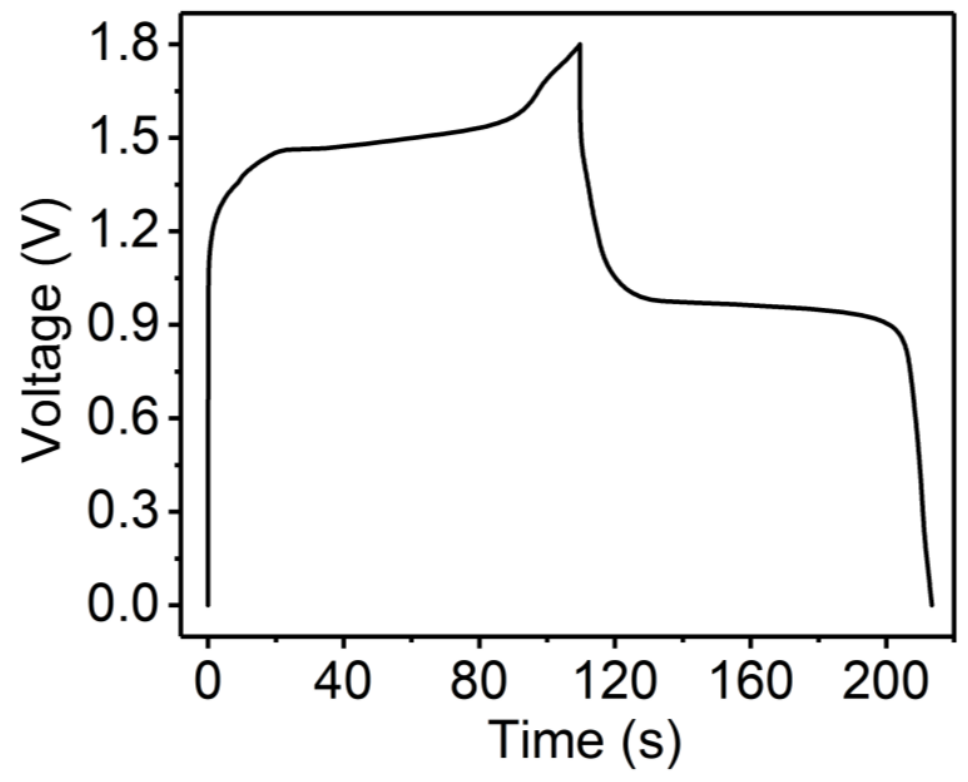

Figure S8. Typical charge-discharge curve of the Ni-Fe full cell at $4 \mathrm{~A} \mathrm{~g}^{-1}$ with a charging voltage of $1.8 \mathrm{~V}$, and the Coulombic efficiency is $95.4 \%$. 


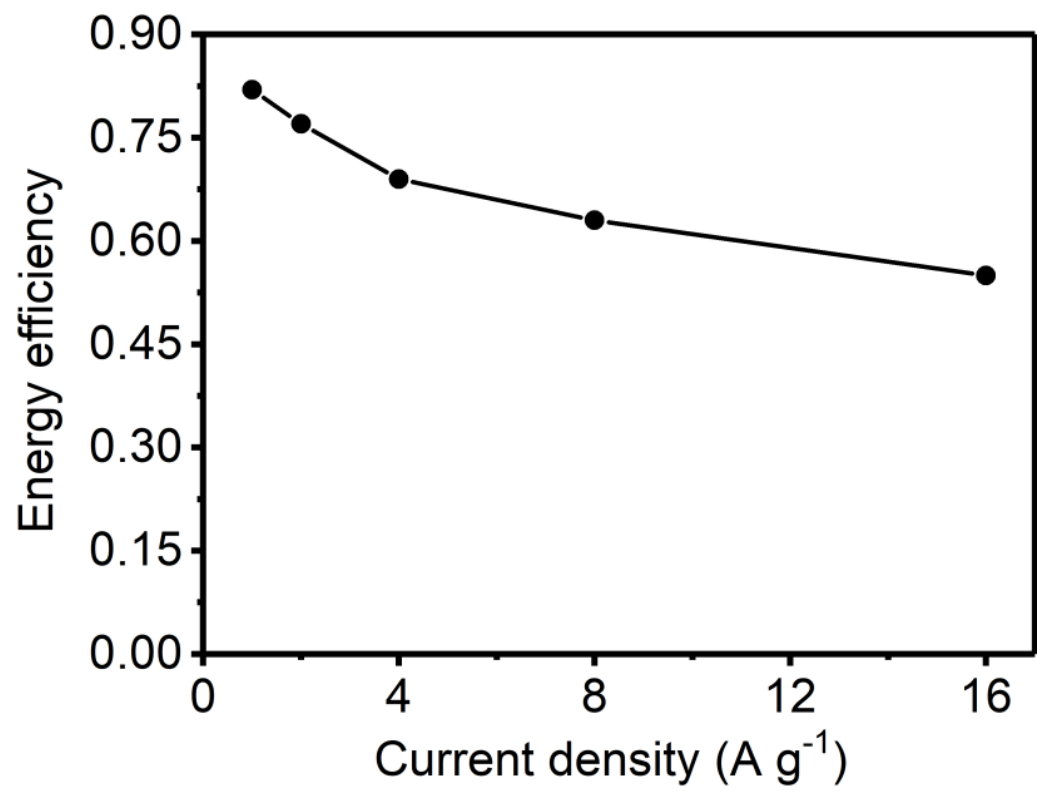

Figure S9. Energy efficiencies of the assembled Ni-Fe full cell at different discharging current densities. All the charging processes were performed with a fixed current density of $4 \mathrm{~A} \mathrm{~g}^{-1}$. 


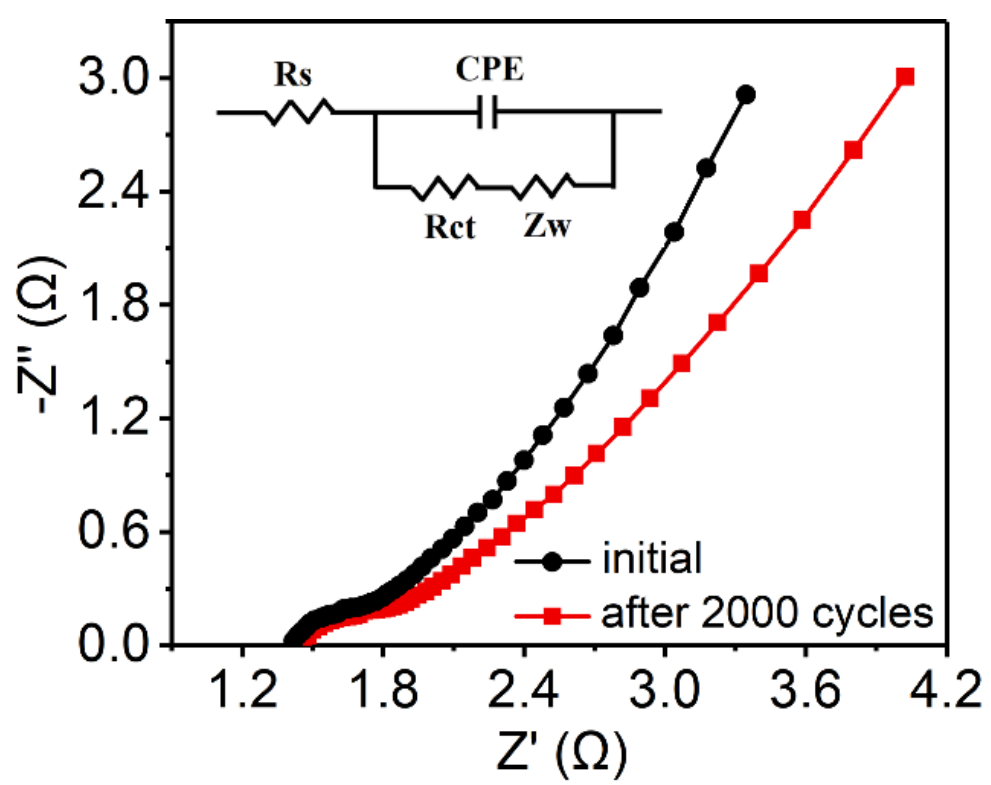

Figure S10. Nyquist plots of the assembled Ni-Fe battery before and after 2000 cycles at the voltage of 1.548 and $1.562 \mathrm{~V}$, respectively. The equivalent circuit used to fit the EIS curves is shown in the inset. 


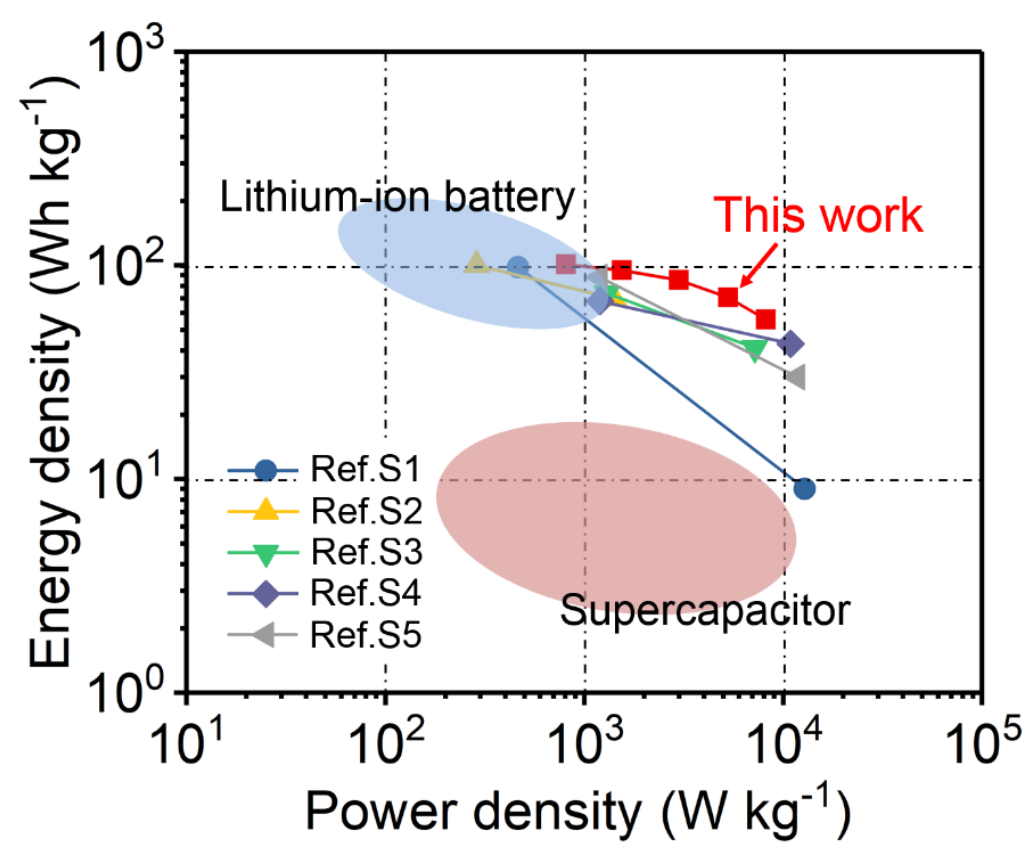

Figure S11. Comparison of Ragone plots of the as-assembled Ni-Fe full cell and the state-of-the-art $\mathrm{Fe}$ anode based full cells results ${ }^{\mathrm{S} 1-5}$.

For the full cell in ref.S1, the anode material was graphene/porous $\mathrm{Fe}_{2} \mathrm{O}_{3}$ nanocomposite (weight ratio of $\mathrm{Fe}_{2} \mathrm{O}_{3}$ is $\sim 68 \%$ ), and $\mathrm{CoNi}$-layered double hydroxide/carbon nanotube composite was used as the cathode (weight ratio of CoNi-layered double hydroxide is not mentioned), the performance in the Ragone plots are based on the mass of the active materials. For the Ni-Fe full cell in ref.S, $\mathrm{Ni}(\mathrm{OH})_{2}$ nanosheets and porous $\mathrm{Fe}_{2} \mathrm{O}_{3}$ nanorods grown on lab-made graphene foam (GF)/carbon nanotubes (CNTs) hybrid films were used as cathode and anode, respectively; Mass loading of the $\mathrm{Ni}(\mathrm{OH})_{2}$ and $\mathrm{Fe}_{2} \mathrm{O}_{3}$ on the hydrid film were 0.58 and $0.48 \mathrm{mg}, \mathrm{cm}^{-2}$, respectively, and the performance was also based on the mass of active materials. For the full cell in ref.S3, $\mathrm{Fe}_{2} \mathrm{O}_{3}$ and $\mathrm{CoMoO}_{4}$ nanoparticles were deposited on the lab-made graphite foam-carbon nanotube framework substrate through an ALD process; the performance was based on the mass of active materials, and mass loading of the active materials was not clear in the paper. For the full cell in ref.S4, carbon-coated Fe nanoparticles was used as the anode, and mixed Co-Cd selenide nanorods fabricated on nickel foam was used as the cathode; the performance was based on the mass of active materials, mass loadings of anode and cathode were 2.5 and $2 \mathrm{mg} \mathrm{cm}^{-2}$, respectively. For the full cell in ref.S5, needle-like $\mathrm{Fe}_{3} \mathrm{O}_{4}$ and flakelike $\mathrm{NiO}$ directly were grown on carbon cloth/carbon nanofiber matrix as the anode and cathode; the performance was based on the mass of active materials, and the mass loading of $\mathrm{Fe}_{3} \mathrm{O}_{4}$ and $\mathrm{NiO}$ were 2 and $2.4 \mathrm{mg} \mathrm{cm}^{-2}$, respectively. For our work, the Ragone plots were all based on the mass of the entire composites, the mass loading of $\mathrm{Fe}$ anode and $\mathrm{Ni}$ cathode was 2.8 and $3 \mathrm{mg} \mathrm{cm}^{-2}$, respectively. These comparisons further suggested the high performance of the assembled Ni-Fe full cell. 


\section{References}

S1. Chen, J.; Xu, J.; Shuang, Z.; Ni, Z.; Wong, C. P. Nano Energy 2015, 15, 719-728.

S2. Liu, J.; Chen, M.; Zhang, L.; Jiang, J.; Yan, J.; Huang, Y.; Lin, J.; Fan, H. J.; Shen, Z. X. Nano Lett 2014, 14, 7180-7187.

S3. Guan, C.; Liu, J.; Wang, Y.; Mao, L.; Fan, Z.; Shen, Z.; Zhang, H.; Wang, J. ACS Nano 2015, 9, 5198-5207.

S4. Zhai, Z.-B.; Huang, K.-J.; Wu, X. Nano Energy 2018, 47, 89-95.

S5. Guan, C.; Zhao, W.; Hu, Y.; Ke, Q.; Li, X.; Zhang, H.; Wang, J. Adv. Energy Mater. 2016, 6, 1601034. 